\title{
Influence of size effects on material properties and springback behavior of metal foils in micro bending: A review
}

\author{
Xiaoyu Liu ${ }^{1}$, Shiping Zhao, ${ }^{1, \mathrm{a}}$, Yi Qin ${ }^{2}$, and Wan Adian Wan Nawang ${ }^{2}$ \\ ${ }^{1}$ School of Manufacturing Science and Engineering, Sichuan University, Chengdu 610065, China \\ ${ }^{2}$ Department of Design, Manufacture \& Engineering Management, University of Strathclyde, \\ Glasgow G1 1XJ, UK
}

\begin{abstract}
With product miniaturization, the requirement on good forming quality and high dimensional accuracy of micro parts is increasing dramatically. In micro bending process, the springback, a critical factor for the accuracy of micro-bent parts, is significantly affected by size effects. In view of the strong influence of material properties on springback behavior, this paper first reviews the influences of three size-dependent factors on material properties, including foil thickness, grain size and thickness to grain size ratio. Afterwards, the review on the influences of these factors on springback behavior are presented, aiming at enhancing the understanding of relevant size effects and proposing a quantitative analysis approach to evaluate the dimensional accuracy of micro-bent parts.
\end{abstract}

\section{Introduction}

The increasing demands for miniaturized parts render great challenges to manufacturing. Micro forming, one of the most promising manufacturing approaches, presents attractive advantages of fabricating metallic micro parts efficiently with high productivity, low production cost and good forming quality [1-4]. With its booming development, the demand on the accuracy of the metallic micro parts is elevating and has stimulated the research on the precision evaluation of micro-formed parts. In terms of micro bending process, the springback, caused by elastic recovery during unloading, is an important factor significantly affects the dimensional accuracy of micro-bent parts $[5,6]$.

Over the past decades, macro-scale bending of metal sheets was widely investigated experimentally, numerically and analytically. Some factors affecting springback such as material properties, tooling geometry and process parameters, have been extensively studied and reviewed [7-9]. However, when the geometry dimension of micro-bent parts is downscaled to micro-scale, the conventional knowledge of macro-scaled bending process could not be directly applied in micro bending due to the so-called size effect $[2,10,11]$. Figure 1 summarizes the size effect related issues in micro bending process. The size effects on material properties in micro bending are characterized by thickness, grain size, thickness to grain size ratio and surface property [12]. These factors have a close relationship with

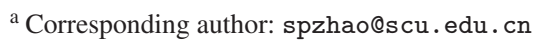

This is an Open Access article distributed under the terms of the Creative Commons Attribution License 4.0, which permits unrestricted use, distribution, and reproduction in any medium, provided the original work is properly cited. 


\author{
Size related parameters \\ - Thickness T \\ - Grain size D \\ - Thickness to Grain size ratio T/D \\ - Surface property
}

\section{1}

Size effect related material properties

- Flow stress

- Yield strength

- Elasticity Modulus

- Strain-hardening

- Formability

$\bullet$

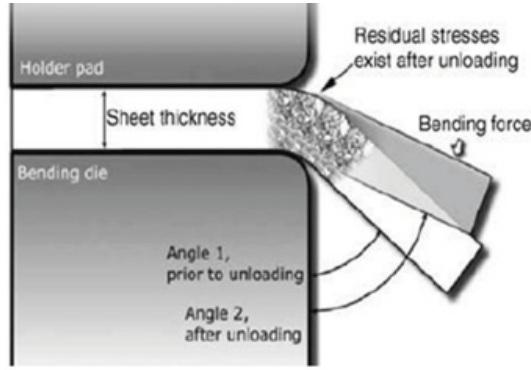

Dimensional performance

- Springback angle

- Springback radius

- Scattering

Figure 1. Size effect related issues in micro bending process.

material properties, which in turn affect the dimensional accuracy of micro-bent parts. According to available literatures, foil thickness and grain size, especially for the ratio of metal foil thickness to grain size, are key factors affecting springback behavior [10, 13, 14]. Nevertheless, few reviews highlighting the influence of the forementioned three factors on material properties and springback angle have been reported.

In this paper, an experiment-based review on influences of thickness, grain size and thickness to grain size ratio on material properties and springback behavior are comprehensively summarized. The paper aims at providing an overall understanding of this issue and laying a foundation of establishing a quantitative analysis approach to evaluate the dimensional accuracy of micro-bent parts in the future.

\section{Size effects on material properties}

According to the classical bending theory [15], material properties, such as flow stress and Young's modulus, are vital factors affecting the springback angle. In order to investigate material properties of metal foils, tensile tests are usually conducted. The obtained flow stress curves, which represent the strength of forming materials, could interpret the influences of size effects on material properties.

\subsection{Effect of thickness on material properties}

Effect of thickness on the flow stress has shown two opposite tendencies. Liu et al. [16] investigated the geometry size effect on material properties of pure copper sheets with thickness ranging from $0.1 \mathrm{~mm}$ to $0.6 \mathrm{~mm}$ by tensile tests. It is found that the flow stress decreases with sheet thickness of similar grain size, as shown in Fig. 2(a). This "thinner is weaker" effect has been verified via different metal sheets, such as aluminum [14] and brass [17]. It is caused by the increasing share of surface grains in the overall volume when the sheet thickness decreases. Since surface grains have a free boundary and cannot hinder the movement of dislocations, they exhibit lower yield strength than grains positioned within the material, contributing to the decrease in material strength.

The opposite tendency is "thinner is stronger" effect, revealing the increasing flow stress with the decreasing thickness of metal foils. Suzuki et al. [18] conducted tensile tests of pure aluminum foils when the average grain size is $48 \mu \mathrm{m}$ and thicknesses range from $20 \mu \mathrm{m}$ to $50 \mu \mathrm{m}$. With the reduction of the thickness, an obvious increase of yield strength is observed in Fig. 2(b). Li et al. [19] have also observed the similar tendency in tensile tests of $\mathrm{CuZn} 37$ brass foils with thickness ranging from 

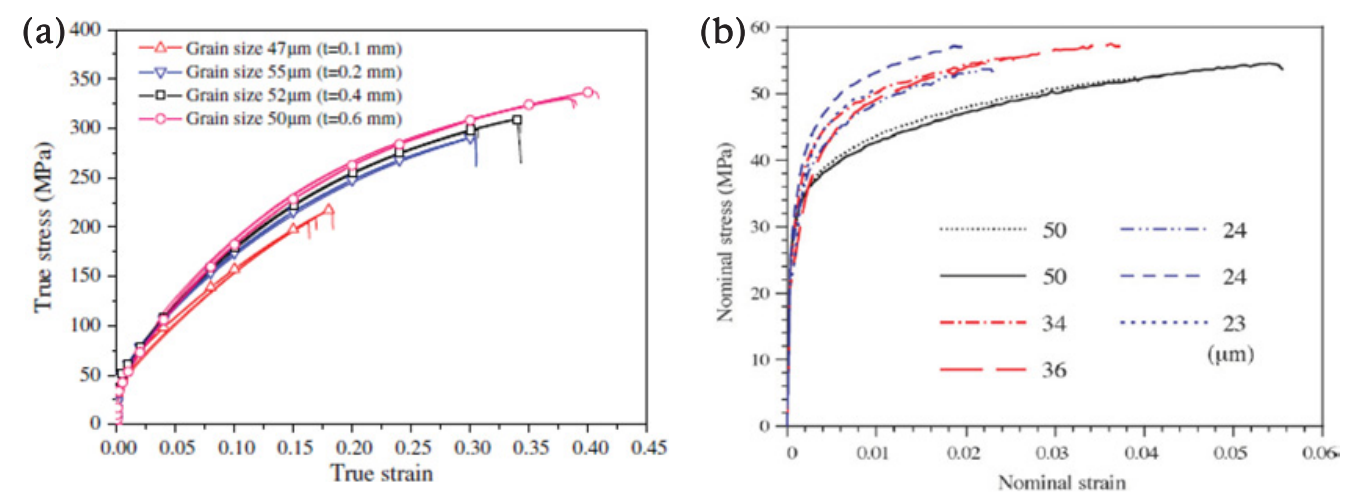

Figure 2. Size effect of metal foil thickness on flow stress with a similar grain size. (a) thinner is weaker effect [16]; (b) thinner is stronger effect [18].

Table 1. Different effects of foil thickness on the material strength.

\begin{tabular}{|c|c|l|c|}
\hline Material & Thickness T $(\boldsymbol{\mu m})$ & Value $(\boldsymbol{\mu m})$ & Effects on material strength \\
\hline \multirow{2}{*}{ Brass H62 [22] } & \multirow{2}{*}{$50,100,250,500$} & $\mathrm{~T}>250$, decrease & decrease \\
\cline { 3 - 4 } & & $\mathrm{T}>250$, decrease & increase \\
\hline \multirow{2}{*}{ Brass C2680 [23] } & \multirow{2}{*}{$20,40,60,80,100$} & $\mathrm{~T}>60$, decrease & decrease \\
\cline { 3 - 4 } & \multirow{2}{*}{$30,50,90,140,190$} & $\mathrm{~T}>60$, decrease & increase \\
\cline { 3 - 4 } & $\mathrm{T}<90$, decrease & decrease \\
\hline \multirow{2}{*}{ Copper T2 [20] } & \multirow{2}{*}{$20,40,80,160,320$} & $\mathrm{~T}>40$, decrease & increase \\
\cline { 3 - 4 } & $\mathrm{T}<40$, decrease & increase \\
\hline \multirow{2}{*}{ Copper T2 [24] }
\end{tabular}

$25 \mu \mathrm{m}$ to $200 \mu \mathrm{m}$. The "thinner is stronger" size effect is most likely simultaneously influenced by both the great inhomogeneous deformation and the high strain gradient $[19,20]$. When the thickness of metal foils decreases to only one or several grains across the thickness direction, anisotropic properties of every single grain become significant to the deformation behavior and lead to the inhomogeneous deformation. This results in an increase in material strength. Additionally, some researchers proposed the strain gradient hardening theory to interpret this size effect. It has been observed that high strain gradient occurs with the foil thickness decreasing, leading to an increase in material strength due to an increasing density of geometrically necessary dislocations [21].

In order to carry out an in-depth investigation on the effect of thickness on the material strength, some researchers conducted tensile tests of the same metal foils with a wide range of thickness and observed both size effects. The experimental results are listed in Table 1.

The reason why the same material exhibits two opposite size effects in the different thickness range is that flow stress and yield strength are influenced by both the surface grain weakening effect and strain gradient hardening effect [24]. When the thickness is large, flow stress and yield strength are mainly influenced by the surface grain weakening effect, representing a decrease with decreasing thickness. Whereas, when the thickness decreases to a certain value, the strain gradient hardening effect dominates the influence, showing the "thinner is stronger" size effect. However, how to determine the thickness threshold of different size effects is an important issue worthy of further study.

\subsection{Effect of grain size on material properties}

Wang et al. [17] investigated three different thicknesses of copper alloy C2680 with different annealing conditions. The flow stress is found to decrease with the increase of grain size when the foil thickness 


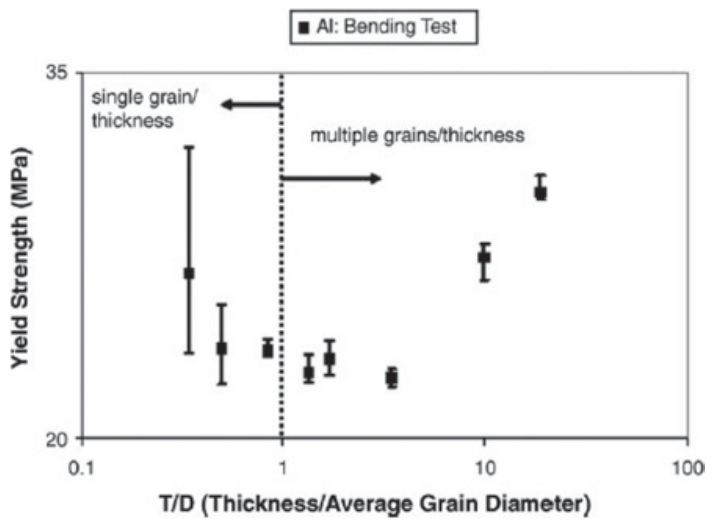

Figure 3. Size effect of T/D ratio on yield strength of aluminum in bending test [27].

keeps constant. This indicates that the grain size effect obviously affects the flow stress of this kind of material. In addition, some prior researches also verified the grain size effect in the copper [25], C2680 brass [23], CuZn37 brass [19], Fe [26], et al.

Generally, the grain size effect is described by the Hall-Petch equation, which states the finer the grain size, the higher the material strength. Another reason accounting for this effect is surface grains have lesser constraints and their flow stresses are relatively lower than those of inner grains. When the average grain size increases, the portion of surface grains increases, thus the flow stress decreases.

\subsection{Effect of thickness to grain size ratio on material properties}

According to the foregoing experimental researches, it is indicated that both the thickness and grain size have strong influences on the material strength. In order to figure out one parameter that could take the interactive influence between the thickness and grain size into consideration, some researchers proposed thickness to grain size ratio (T/D ratio), which represents the average grain number across the thickness direction, to investigate the influence of size effect on material properties.

According to tensile and bending tests of aluminum 1100 and brass 26000 conducted by Gau et al. [27], as shown in Fig. 3, for T/D $>1$, the yield strength decreases with the decrease in T/D ratio; for $\mathrm{T} / \mathrm{D}<1$, the yield strength increases with the decrease in T/D ratio. This is because when the thickness downscales to the same magnitude as the grain size, mechanical properties of individual grains in the plastic zone have an increasing influence on the forming behavior, resulting in a trend of the increase in yield strength. Similarly, Raulea et al. [14] observed this trend in experiments of aluminum sheets.

\section{Size effects on springback angle}

\subsection{Effect of thickness on springback angle}

The investigations of how foil thickness affects springback angle are usually conducted by three-point bending [16, 28, 29], V-bending [30], U-bending [17] and free-bending experiments [10, 20, 31].

Wang et al. [30] studied the springback in three-point bending experiments of C2680 brass foils with thicknesses of 40, 60, 80 and $100 \mu \mathrm{m}$. It is observed that foil thickness is the most vital factor affecting the springback angle which increases with the decrease of foil thickness. Wang et al. [17] conducted micro U-bending experiments of C2680 brass with thicknesses ranging from 100-400 $\mu \mathrm{m}$ and found the springback angle increases with the decrease of foil thickness no matter how large the grain size is. 
Diehl et al. [10] and Li et al. [31] carried out scaled micro free-bending experiments of pure aluminum foils with thicknesses ranging from $25 \mu \mathrm{m}$ to $500 \mu \mathrm{m}$. In the experiments, springback angle is found to increase with the decreasing foil thickness, which is attributed to the plastic strain gradient hardening effect.

\subsection{Effect of grain size on springback angle}

Diehl et al. [10] investigated the influence of grain size on the springback angle of pure aluminum foils with various thicknesses (25-200 microns) by free bending tests. Different heat treatments were conducted to obtain fine and coarse grains. It is revealed that when the thickness keeps constant, the springback angle decreases with the increasing grain size. This phenomenon could be interpreted by the surface layer model. For the same thickness of metal foils, an increasing share of surface grains occurs when grain size increases thus presenting a reduced resistance against the plastic deformation. Due to the enlarged plastic zone and shrunk elastic zone, the springback angle which is caused by elastic recovery decreases. Similar results were found in [20, 29]. In addition, Wang et al. [32] verified the influence of grain size on springback angle in micro free-bending by numerical simulation.

\subsection{Effect of thickness to grain size ratio on springback angle}

Gau et al. [28] conducted three-point bending experiments to study the springback behavior of C26000 brass sheet. It is found that the springback angle could be expressed as a function of T/D ratio, which decreases with an increase of T/D ratio. The similar tendency was also reported in [29].

However, some different experimental results are observed as well. Chen and Jiang [26] adopted T/D ratio to investigate the springback behavior in micro V-bending test and found that for the constant grain size, the springback angle decreases with an increase in T/D ratio. For the constant thickness, nevertheless, the springforward occurs when T/D ratio is less than 2, as shown in Fig. 4(a). Liu et al. [16] also carried out three-point bending tests using copper foils to study the interactive effect between foil thickness and grain size. As shown in Fig. 4(b), the springback angle decreases with the increasing T/D ratio, which is consistent with forementioned results. Whereas, they observed that the springback angle does not monotonously vary with T/D ratio. With almost the same T/D ratio, the metal foil with $\mathrm{T}=0.4 \mathrm{~mm}$ and $\mathrm{D}=132 \mu \mathrm{m}$ has much smaller springback angle than those foils with $\mathrm{T}=0.2 \mathrm{~mm}$ and $\mathrm{D}=55-75 \mu \mathrm{m}$. The main reason is when the thickness difference is large even though they have the same T/D ratio, the thickness is a decisive factor affecting the springback angle. Therefore, the springback behavior could not be interpreted only by T/D ratio.

\section{Conclusions}

Micro bending is one of the most widely used processes in micro forming. The springback, a prominent factor affecting the dimensional accuracy of micro-bent parts, is significantly influenced by size effects. In order to evaluate the dimensional accuracy of micro-bent parts, it is important to investigate how size effects and springback influence each other during micro bending process. For this purpose, a review based on experimental researches is reported focusing on the influence of foil thickness, grain size and thickness to grain size ratio on material properties and springback behavior.

Available researches have demonstrated that abovementioned factors have significant influences on material properties and springback angle, however, most conclusions were drawn by qualitative description based on experimental results rather than quantitative analysis. Therefore, a series of experiments of brass foils are being carried out to extensively investigate the influence of foil thickness, grain size and thickness to grain size ratio on material properties and springback behavior with a view to 

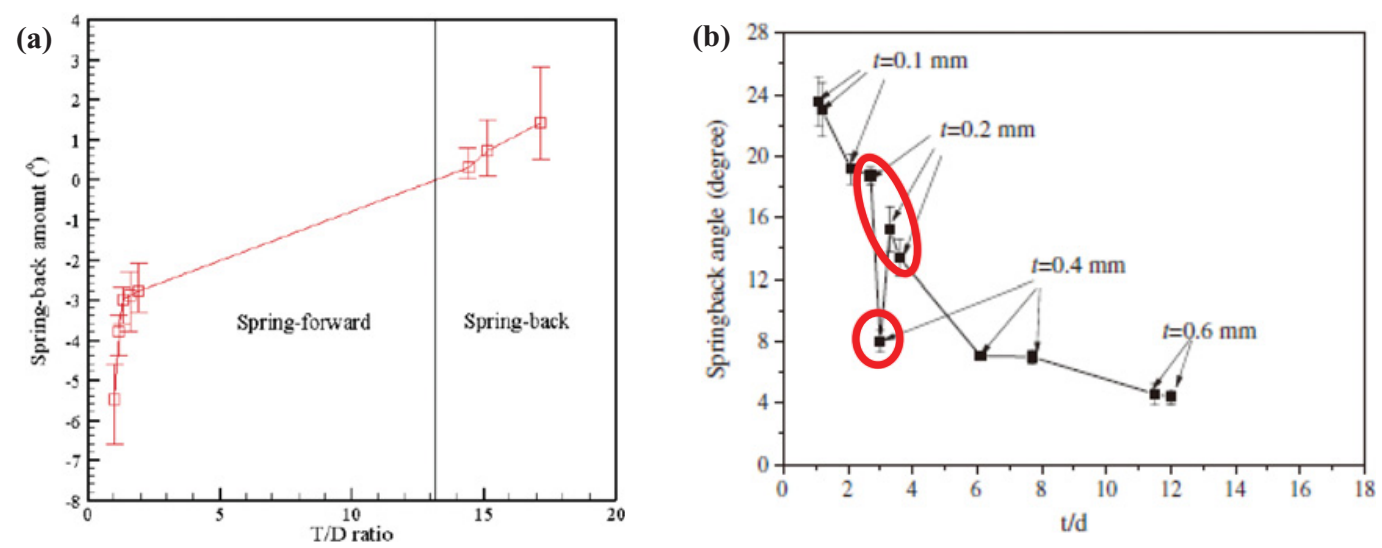

Figure 4. Influence of T/D ratio on springback angle in (a) and (b) $[16,26]$.

proposing a quantitative analysis approach to evaluate and control the dimensional accuracy of microbent parts.

The authors would like to acknowledge the financial supports from the Specialized Research Fund for the Doctoral Program of Higher Education of China (No. 20110181110084) and Chinese Scholarship Council. The authors also gratefully thank experimental supports from the University of Strathclyde.

\section{References}

[1] M. Geiger, M. Kleiner, R. Eckstein, N. Tiesler, U. Engel, CIRP Ann.-Manuf. Techn. 50, 445 (2001)

[2] U. Engel, R. Eckstein, J. Mater. Process. Tech. 125, 35 (2002)

[3] F. Vollertsen, Z. Hu, H.S. Niehoff, C. Theiler, J. Mater. Process. Tech. 151, 70 (2004)

[4] Y. Qin, Micromanufacturing engineering and technology (William Andrew, 2010)

[5] J. Jeswiet, M. Geiger, U. Engel, M. Kleiner, M. Schikorra, J. Duflou, ... S. Bruschi, CIRP J. Manuf. Sci. Technol. 1, 2 (2008)

[6] M.W. Fu, W.L. Chan, Mater. Design 49, 774 (2013)

[7] Z. Tekiner, J. Mater. Process. Tech. 145, 109 (2004)

[8] I.A. Choudhury, V. Ghomi, Proc. Inst. Mech. Eng. Part B J. Eng. Manuf, 0954405413514225 (2013)

[9] S.B. Chikalthankar, G.D. Belurkar, V.M. Nandedkar, Int. J. Eng. Adv. Technol. 3, 247 (2014)

[10] A. Diehl, U. Engel, M. Geiger, Multi-Mater. Micro Manuf, 147 (2005)

[11] F. Vollertsen, D. Biermann, H.N. Hansen, I. S. Jawahir, K. Kuzman, CIRP Ann.-Manuf. Techn. 58, 566 (2009)

[12] Q. Wang, X.H. Dong, H.M. Zhang, H.Z. Li, Y. Shen, T. Nonferr. Metal Soc. 23, 1428 (2013)

[13] P. Cavaliere, F. Gabrielli, L. Fratini, Proc. 8th Int. Conf. Metal Forming, 405 (2000)

[14] L.V. Raulea, A.M. Goijaerts, L.E. Govaert, F.P.T. Baaijens, J. Mater. Process. Tech. 115, 44 (2001)

[15] W. Johnson, P.B. Mellor, Engineering plasticity (Van Nostran Reinhold Company, London, 1973)

[16] J.G. Liu, M.W. Fu, J. Lu, W.L. Chan, Comp. Mater. Sci. 50, 2604 (2011)

[17] J.L. Wang, M.W. Fu, J.Q. Ran, Adv. Eng. Mater. 16, 421 (2014)

[18] K. Suzuki, Y. Matsuki, K. Masaki, M. Sato, M. Kuroda, Mat. Sci. Eng. A-Struct. 513, 77 (2009) 


\section{ICNFT 2015}

[19] H.Z. Li, X.H. Dong, Y. Shen, R. Zhou, A. Diehl, H. Hagenah, .. J. Cao, J. Mater. Process. Tech. 212, 653 (2012)

[20] H. Jiang, Numerical simulation and experimental research on micro bending process of pure copper foil (MSc dissertation, Shandong University, 2013)

[21] N.A. Fleck, J.W. Hutchinson, Adv. Appl. Mech. 33, 295 (1997)

[22] L. Yu, P. Li, K.M. Xue, D. Wei, Mater. Mech. Eng. 34, 69 (2010)

[23] B. Guo, J. Zhou, D.B. Shan, H.M. Wang, Acta. Metall. Sin. 44, 419 (2009)

[24] J. Zhou, Research on size effects of mechanical property and micro deep drawing of copper foil ( $\mathrm{PhD}$ dissertation, Harbin Institute of Technology, 2010)

[25] W.L. Chan, M.W. Fu, J. Lu, J.G. Liu, Mat. Sci. Eng. A-Struct. 527, 6638 (2010)

[26] C.C. Chen, C.P. Jiang, Mater. Manuf. Processes 26, 78 (2011)

[27] J.T. Gau, C. Principe, J. Wang, J. Mater. Process. Tech. 184, 42 (2007)

[28] J.T. Gau, C. Principe, M. Yu, J. Mater. Process. Tech. 191, 7 (2007)

[29] C.J. Wang, X.W. Wang, B. Guo, D.B. Shan, Mater. Sci. Technol. 17, 5 (2009)

[30] A.B. Abdullah, Z. Samad, IOP Conf. Ser. Mater. Sci. Eng. 50, 012069 (2013)

[31] H.Z. Li, X.H. Dong, Y. Shen, A. Diehl, H. Hagenah, U. Engel, M. Merklein, Mat. Sci. Eng. A-Struct. 527, 4497 (2010)

[32] Y. Wang, P.L. Dong, Z.Y. Xu, J.P. Wu, Y.S. Zhu, G.H. Lu, J. Exp. Mech. 24, 177 (2009) 